\title{
ТОРГОВЫЙ БАЛАНС КАК ПОКАЗАТЕЛЬ ЭКОНОМИЧЕСКОГО РАЗВИТИЯ (НА ПРИМЕРЕ СТРАН СКАНДИНАВИИ)
}

Ермошкин Артём Евгеньевич Научный руководитель: Миркина Ольга Наумовна к.э.н., доцент ФГБОУ ВО «Смоленский государственный университет»

Аннотация: в статье предпринята попытка анализа сальдо торгового балансаскандинавских стран: Норвегии, Швеции и Дании. В частности, проанализированы структура экспорта и импорта стран Скандинавии, оценены отдельные макроэкономические показатели.

Ключевые слова: экспорт, импорт, макроэкономические показатели, сальдо торгового баланса, скандинавские страны.

\section{THE TRADE BALANCE AS AN INDICATOR OF ECONOMIC DEVELOPMENT (IN THE CASE OF SCANDINAVIAN COUNTRIES)}

\author{
Yermoshkin Artyom Evgenievich \\ Scientific adviser: Mirkina Olga Naymovna
}

\begin{abstract}
Scandinavian countries, such as Norway, Sweden and Denmark in this article. The structures of export and import were analyzed too. Also we estimated the other macroeconomic indicators.

Key words: export, import, macroeconomic indicators, trade balance, Scandinavian countries.

Европейские страны ассоциируется у большинства людей с эталоном международного сотрудничества. В связи с этим, в своей риторике используют термин «семья» в качестве определения статуса и принципа взаимодействия и взаимоотношений внутри. Однако, путь развития каждого члена данной «семьи» различен как в экономическом, правовом, так и в социальном плане. Одной из привлекательных для обсуждения групп являются страны Северной Европы, а именно Финляндия, Исландия, Дания,
\end{abstract}


Норвегия и Швеция. Последние три относятся к категории скандинавских стран и заслуживают отдельного внимания.

Скандинавские страны на протяжении длительного периода времени являются одними из устойчивых и успешных стран мира. Согласно ежегодному международному докладу ООН «WorldHappinessReport 2019»[3], данная групп стран стабильно входит в десятку лидеров.

Так, Норвегия заняла первые места мировых рейтингов по индексу человеческого развития в 2018 году (HumanDevelopmentindex 2018) и свободы прессы в 2019 году (WorldPressFreedomIndex 2019). Также, в 2019 году Норвегия показала высокие результаты в рейтинге инновационных экономик мира. Швеция и Финляндия вошли в топ 10 стран мира по показателям глобальной конкурентоспособности 2017-2018 гг. (GlobalCompetitivenessIndex). В 2019 году Исландия стала одной из самых экономически свободных стран мира, заняв в соответствующем рейтинге 11 место. Дания по данным на 2018 год стала мировым лидером по восприятию коррупции (Corruptionperceptionindex 2018), а в 2019 год оказалась в тройке лидеров стран, наиболее подходящих для ведения бизнеса [2]. О высоком уровне развития скандинавских стран свидетельствуют и макроэкономические показатели [4,5], представленные в Таблице 1.

Таблица 1

Макроэкономические показатели развития стран Европы (фрагмент)

\begin{tabular}{|c|c|c|c|}
\hline \multirow{2}{*}{ Показатели } & \multicolumn{3}{|c|}{ Скандинавские страны } \\
\hline & Швеция & Норвегия & Дания \\
\hline ВВП, млрд.долл. & 565 & 355 & 347 \\
\hline ВВП на душу населения, долл. & 55265 & 66214 & 59719 \\
\hline Доля в мировом ВВП,\% & $\begin{array}{c}0,39 \\
(-0,01)^{*}\end{array}$ & $\begin{array}{c}0,28 \\
(-0,01)^{*}\end{array}$ & 0,21 \\
\hline Экспорт, млрд.долл & 160,5 & 104 & 109,9 \\
\hline Импорт, млрд.долл & 158,7 & 86 & 97,2 \\
\hline Сальдо ТБ, млрд.долл. & 1,8 & 18 & 12,7 \\
\hline Средняя з/п,долл. & 5038 & 6300 & 6610 \\
\hline Макс.размерналогоблажения , \% & 60,1 & 46,7 & 55,8 \\
\hline Налоговая нагрузка, \% ВВП & 44 & 38,2 & 46 \\
\hline Индекс потребительских цен & $\begin{array}{c}110,51 \\
(+1,94)^{*}\end{array}$ & $\begin{array}{c}120,27 \\
(+2,55)^{*}\end{array}$ & $\begin{array}{c}110,35 \\
(+0,83)^{*}\end{array}$ \\
\hline
\end{tabular}

$(*)$ - изменения относительно аналогичного показателя 2018 года. 
И это несмотря на то, что с момента своего формированияНорвегия, Швеция и Дания находились и развивались в заведомо более жестких условиях, чем другие страны Европы.

Географическое положение и климатические условия данных стран, детерминирующие в определенной степени экономическое развитие довольно своеобразны. Скандинавский ландшафт - это величественные фьорды, фьельды, бескрайние леса и луга. Здесь непродолжительный вегетационный период, избыточное увлажнение, сложная литогенная структура и ледниковый ландшафт. Обозначенные особенности с одной стороны подчеркивают туристский потенциал этих стран, но также объясняют ограниченное развитие других сфер экономики, в частности сельского хозяйства.

Согласно мнению Аджемоглу и Дарона «история показывает, что не существует простой и долгосрочной связи между климатом и географией с одной стороны и экономическим процветанием - с другой...» [1, стр.73].И это доказывают скандинавские страны.

Несмотря на все трудности организации хозяйственной деятельности, они смогли стать одними из ведущих стран мира, занимают лидирующие позиции в мировых рейтингах и продолжают свое развитие нарастающими темпами.

Нам представляется, целесообразно, проанализировать такой макроэкономический показатель как сальдо торгового баланса, позволяющий оценить особенности экспортной политики этих стран.

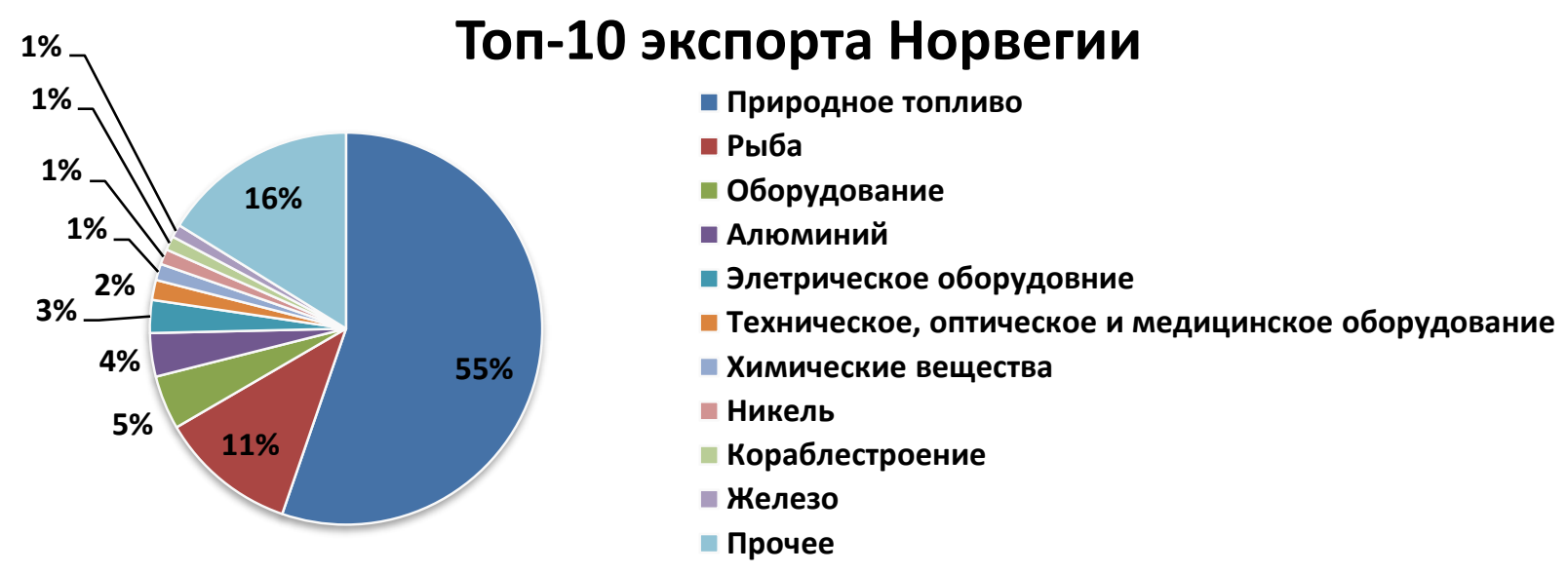

Рис. 1. Топ-10 экспорта Норвегии

Большая доля экспорта Норвегии (рис.1) приходится на категорию природного топлива, в том числе нефтяных продуктов. Одной из причин может служить обнаружение в 2011 году крупных залежей природного 139 
ресурса в водах Норвегии к северу от Северного полярного круга, которые продолжают разрабатываться по настоящее время. Однако, в 2019 году наблюдается снижение доли экспорта минерального топлива, в том числе нефти. Данное значение показателя (57,1 млрд. доллр.) одно из самых низких за последние 30 лет в истории Норвегии. Объём экспорта сильно снизился по сравнению с 2018 годом, более чем на 25\%. Наибольший рост в 2019 году по сравнению с 2018 годом наблюдался в экспорте оптического и медицинского оборудования, он составил $20,8 \%$. Также, достаточно большому росту подвергся экспорт органических веществ и машинного оборудования на $16,1 \%$ и $5,8 \%$ соответственно.

\section{Топ-10 импорта Норвегии}
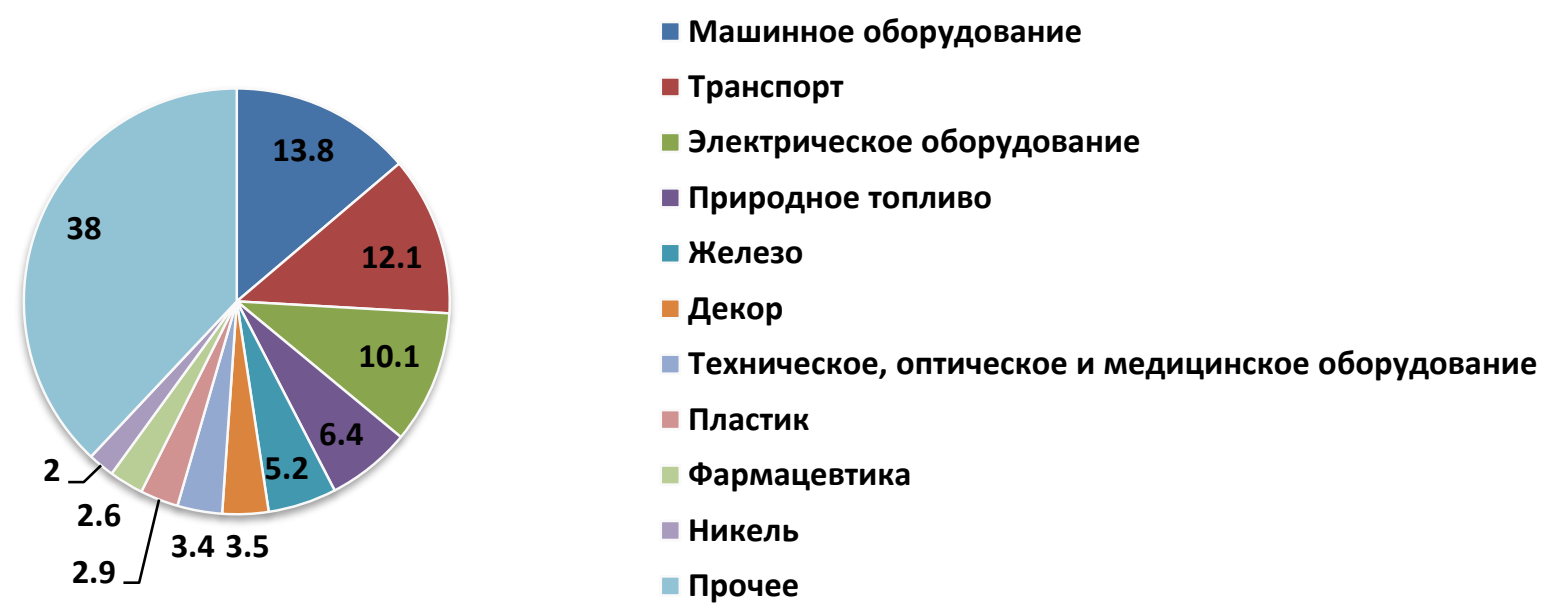

Рис. 2. Топ-10 импорта Норвегии

Объем импортируемых Норвегией товаров (рис.2) составляет 86 млрд. доллар. Наибольшая доля импорта приходится на машинное оборудование $13,8 \%$. Наибольший прирост объемов ввоза наблюдается у электрического оборудование, он вырос на 7,4\% по сравнению с показателями 2018 года. Дынный продукт входит в тройку лидеров по объему импорта данной страны. Также, наблюдается рост в ввозе технического, оптического и медицинского оборудования и автомобилей на $5 \%$ и $1,4 \%$ соответственно. По сравнению с предшествующем периодом, доля ввоза железа, фармацевтики и никеля сократилась на $7,8 \%, 6.5 \%$ и 5,5\% соответственно. 


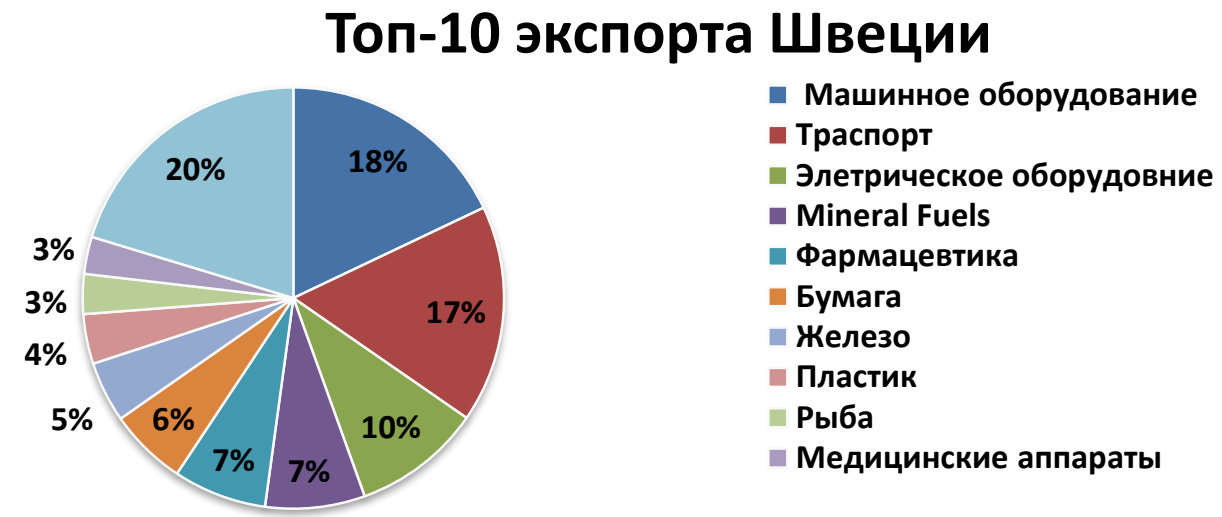

\section{Рис. 3. Топ-10 экспорта Швеции}

В 2019 году лидером по экспорту в Швеции выступало машинное оборудование, экспорт которого составил 25.8 млрд.доллар. и $16 \%$ от общего объёма вывозов товаров из страны. (рис.3).Самый высокий показатель роста показывает экспорт фармацевтической категории, он вырос почти на $19 \%$ и составил 10,3 млрд.доллар. Вторую позицию по темпу росту занял экспорт оптических и медицинских аппаратов - 2,6\%.Третью - экспорт средств передвижения сростомна $1,6 \%$.

\section{Топ-10 импорта Швеции}
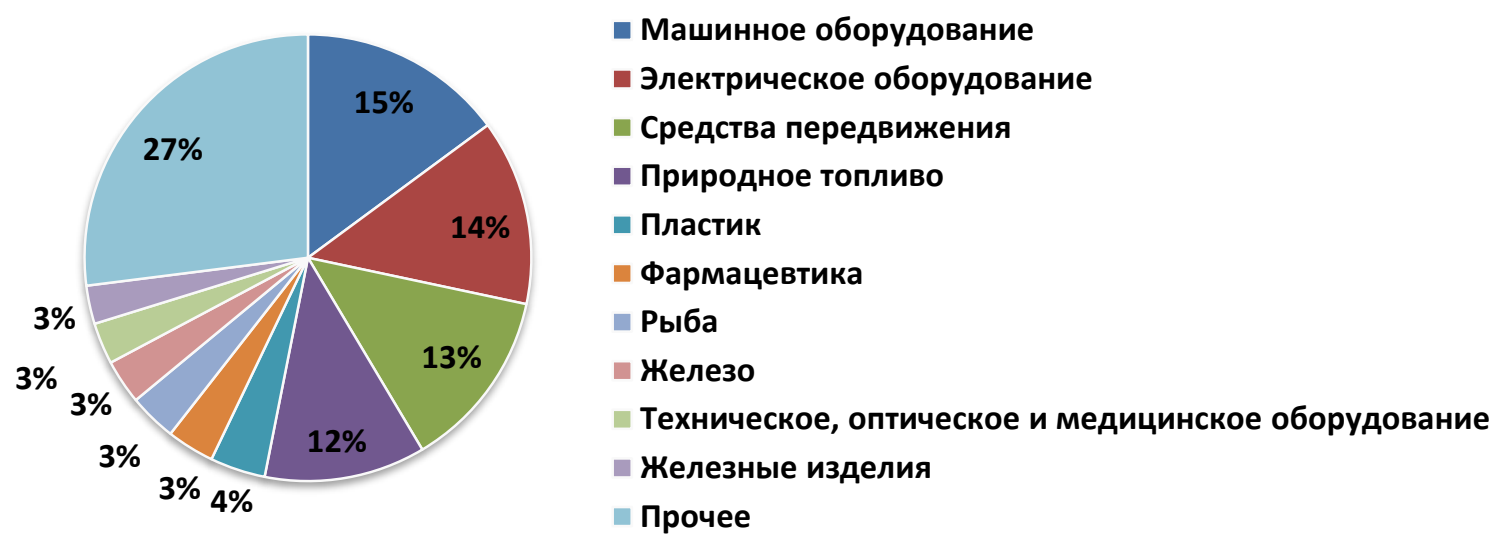

\section{Рис. 4. Топ-10 импорта Швеции}

В 2019 году на свою территорию Швеция ввезла товаров на сумму 157,8 млдрд.доллар (рис.4). В больших объёмах ввозилось машинное оборудование на сумму 21,3 млрд.доллар., что составило 13,4\% общего объема импорта в стране. Три категории товаров показали наивысший прирост по сравнению с аналогичным периодом 2018 года, а именно техническое, медицинское оборудование и оборудование для оптики $(7,9 \%)$, фармацевтика $(6,8 \%)$ и 
пластик $(0,3 \%)$. Наблюдалась тенденция снижения импорта природного топлива и нефти включительно на 17,8\%.

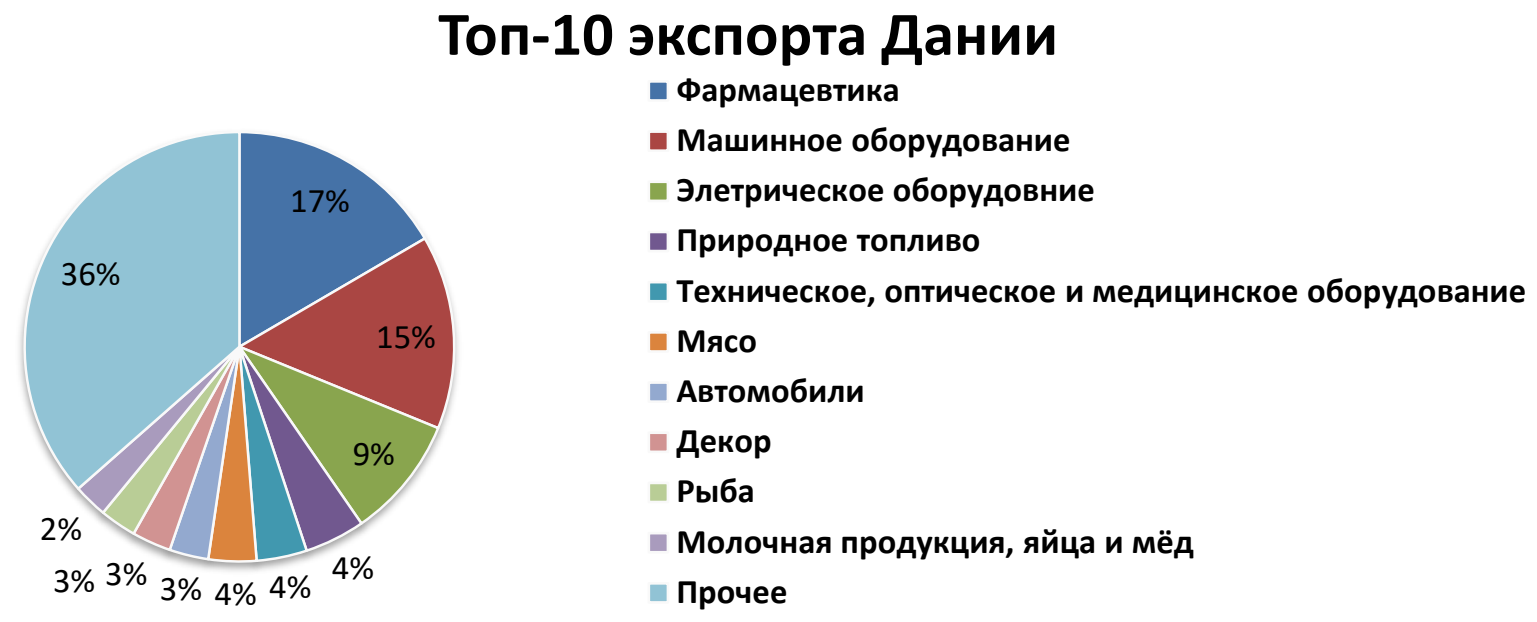

Рис. 5. Топ-10 экспорта Дании

Объем экспортируемых товаров Данией в 2019 году превысил 109 млрд.доллар.(рис.5). Основную долю составил экспорт фармацевтических препаратов - 17,5 млрд.доллар.. Также данная категория показала наибольший рост за период 2018-2019 гг., который составил 21,5\%. Второе место по темпам роста принадлежит категории электрическому оборудованию - 11,1\%. Третье - машинному оборудованию - 5,3\%. Уменьшились объемы экспорта природного топлива, в том числе и нефти на 11,3\%. Данная тенденция, сокращение импорта топливного сырья характерна для всех трех анализируемых стран, и связана, возможно с мировым спадом в экономике и закономерным сокращением потребления энергоресурсов.

\section{Топ-10 импорта Дании}
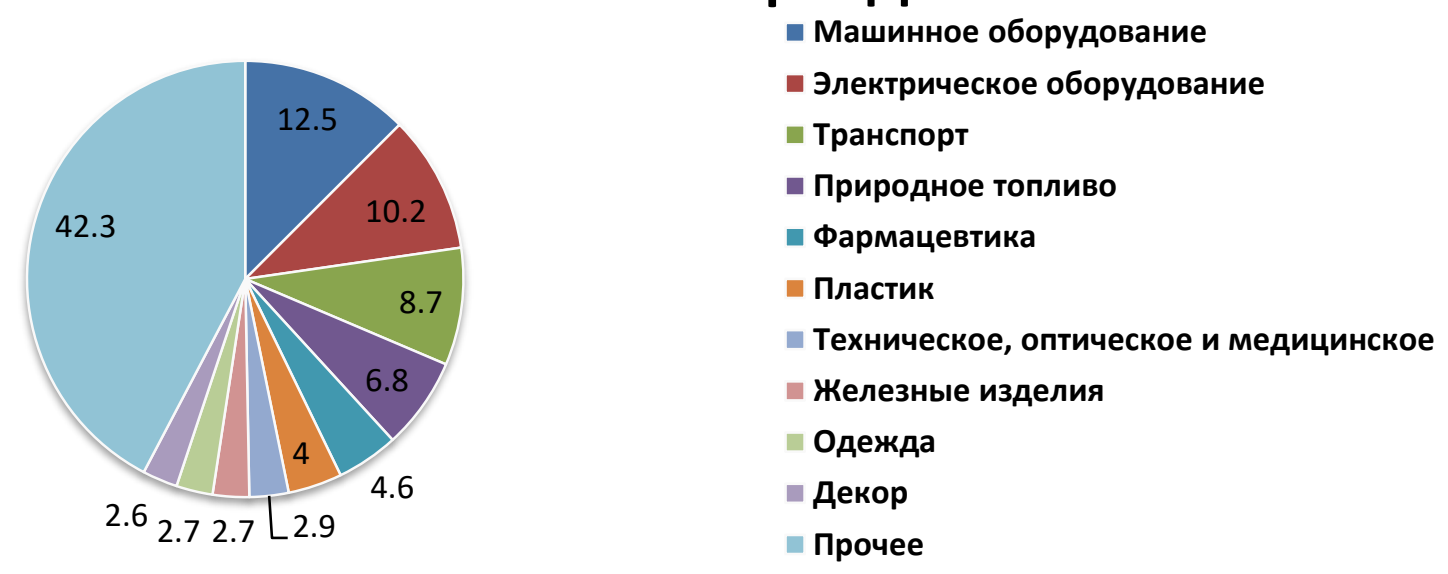

Рис. 6. Топ-10 импорта Дании 
Объем импортных товаров в Дании превышает 92 млрд.доллар.(рис.6). Основную его долю составляет категория машинного оборудования-12,\%; Категории электрического оборудования и оптического, технического и медицинского оборудования показали наилучший прирост за 2019 год, 3,7\% и $1,4 \%$ соответственно. Наибольшее сокращение объёмов импорта наблюдается у категории пластика, на 8,2\%. Что, возможно, является целенаправленным, и объясняется активным процессом экологизации всех сфер экономики в стране.

Скандинавские страны характеризуются положительным торговым балансом. Наиболее высокие показатели характерны для Норвегии (18 млрд.доллар). Необходимо подчеркнуть, что достигается данный показатель за счёт относительно невысоких показателей импорта. Очевидно, что экспорт Норвегии, в значительно степени определен её природными ресурсами, а импорт потребностями отраслевой специализации. Швеция демонстрирует самые высокие цифры экспорта и импорта, близкие по значению. Дания отличается структурой экспорта и импорта от своих скандинавских соседей, но при этом также имеет активный торговый баланс.

Таким образом, показатели торгового баланса свидетельствуют об активной внешней торговой деятельности, эффективной экономической политике, что является важным фактором устойчивого экономического развития скандинавских стран.

\section{Список литературы}

1. Д.Аджемоглу, Дж. Робинсон. Почему одни страны богатые, а другие бедные. Происхождение власти, процветания и нищеты/ / ISBN 978-5-1092736-4;

2. Doing Business 2019/ International Bank for Reconstruction and Development / The World Bank 1818 H Street NW, Washington DC 20433/ www.worldbank.o The Global Innovation Index 2020:

3. World Happiness Report 2019/ John Helliwell, Richard Layard, Jeffrey D. Sachs, and Jan Emmanuel De Neve, Co-Editors; Lara Aknin, Haifang Huang and Shun Wang, Associate Editors; and Sharon Paculor, Production Editor/

4. Интернет ресурс: URL: https://trendeconomy.com/data/h2/Norway/ TOTAL\#: :text=Norway's\%20Top\%20Exports\%20in\%202019,fish\%20meat\%20of $\%$ 20heading\%2003.04. [Дата обращения: 14.12.2020]

5. Интернет ресурс: URL: http://www.worldstopexports.com/ [Дата обращения: 15.12 .2020$]$

() Ермошкин A.Е. 2020 